Research Article

\title{
Sensitivity pattern of bacteria causing respiratory tract infections in a tertiary care centre
}

\author{
Siddalingappa $\mathrm{CM}^{1 *}$, Kalpana $\mathrm{L}^{2}$, Sagar Puli ${ }^{3}$, Vasudha $\mathrm{TK}^{4}$, Abhishek Acharya ${ }^{1}$
}

${ }^{1}$ Department of Pharmacology, Subbaiah Institute of Medical

Sciences, Shimoga, Karnataka, India

${ }^{2}$ Department of Pharmacology, BGS Medical College, Bangalore, Karnataka, India ${ }^{3}$ Department of Pharmacology, Narayana Medical College, Nellore, AP, India

${ }^{4}$ Department of Anatomy, Subbaiah Institute of Medical Sciences, Shimoga, Karnataka, India

Received: 18 July 2013

Accepted: 4 August 2013

*Correspondence to:

Dr. Siddalingappa CM, Email: siddhu1969@gmail.com

(C) 2013 CM Siddalingappa et al. This is an open-access article distributed under the terms of the Creative Commons Attribution Non-Commercial License, which permits unrestricted non-commercial use, distribution, and reproduction in any medium, provided the original work is properly cited.

\section{ABSTRACT}

Background: Respiratory tract infections (RTIs) are one of the major public health problems and a leading cause of morbidity and mortality in many developing countries. A better understanding of pathogens that cause RTIs is important to select appropriate antimicrobials. In recent years, due to inappropriate use of antimicrobials there is spread of bacterial resistance. The present study was designed to analyze the etiological agents of RTIs and their susceptibility pattern to some commonly prescribed antibiotics.

Methods: The study was conducted in Narayana Medical College Hospital of Nellore in Andhra Pradesh in South India from January 2011 to November 2011. Patients who were clinically suspected of having RTIs were included in the study. Sputum or throat swab samples were collected aseptically from the patients and subjected to testing and antibiotic sensitivity.

Results: Out of 466 samples $54.9 \%$ were males and $45.1 \%$ were females. Most prevalent microbes were Klebsiella spp. (51.1\%) and least prevalent microbe was enterococci $(1.3 \%)$. Bacteria were highly sensitive to Meropenem, Imipenem, Piperacillin with Tazobactum and were resistant to Penicillin G, Ampicillin, Cotrimoxazole and Cefepime.

Conclusion: RTIs are one of the most common health problems in developing countries. Various drugs are being used in the treatment of RTIs, in the mean time resistance to many of them are emerging. An appropriate antibiotic has to be initiated only after culture sensitivity in RTIs.

Keywords: Antimicrobial susceptibility, Bacteria, resistance, Respiratory tract infections

\section{INTRODUCTION}

Respiratory tract infections (RTIs) are among the most common infectious diseases affecting humans worldwide. $^{1} \quad$ Respiratory tract infection (RTI) is considered as one of the major public health problems and a leading cause of morbidity and mortality in many developing countries. $^{2-4}$ Acute respiratory infections (ARI) and Tuberculosis were two of the six leading causes of death across all ages. ${ }^{5}$
It is notable that respiratory tract infections cause more disease and death than other infections in the United States. ${ }^{6}$ Age, gender, and season are factors that have been implicated to affect the prevalence of RTIs .The most infections are limited to the upper respiratory tract and only $5 \%$ involve the lower respiratory tract, respectively. Upper Respiratory Tract infections (URTIs) involve the nasal passages, pharynx, tonsils and epiglottis. Lower respiratory tract infections (LRTIs) involve the bronchi and alveoli. They include two serious 
conditions-acute bronchitis and pneumonia. Respiratory diseases have a significant economic impact on the sick individuals in terms of loss of productivity and also on physicians who most of the time have to give antibiotics even if the causative agents are not bacteria.

A better understanding of the pathogens that cause these infections is recognized as a requirement which should allow a logical approach to treatment. There is a need, particularly in developing countries like India, for timely diagnosis of the major microbial causes of the respiratory infections in the community, and the administration of appropriate therapy based on the antibiotic susceptibility test of the causative agent in order to prevent further spread of the pathogen, which might otherwise lead to complications. ${ }^{7}$ In the last three decades, there have been a lot of reports in the scientific literature on the inappropriate use of antimicrobial agents and the spread of bacterial resistance among microorganisms causing respiratory tract infections. ${ }^{8-11}$ The consequences of increased drug resistance are far reaching since bacterial infection of respiratory tract is a major cause of death due to infectious disease. ${ }^{12}$ Nevertheless, the choice for antimicrobial therapy is usually straight forward when the etiologic agents and their susceptibility patterns are known. ${ }^{13}$ Current knowledge of the organisms that cause RTIs and their antibiotic susceptibility profiles are therefore necessary for the prescription of appropriate therapy.

The most common bacteria implicated as causative agents of RTIs were included but not limited to Pseudomonas spp., Streptococcus spp., Proteus spp., Klebsiella spp., Staphylococcus spp., Enterobacter spp., Acinetobacter spp., and Haemophilus influenza. ${ }^{14,15}$

In India, just as in the other parts of the developing world, most RTIs are treated empirically, possibly because of higher cost of laboratory services where available and time factor. The emergence of antibiotic resistance in the management of RTIs is a serious public health issue, particularly in the developing world apart from high level of poverty, ignorance and poor hygienic practices; there is also high prevalence of fake and spurious drugs of questionable quality in circulation.

Antibiotic resistance often leads to therapeutic failures of empirical therapy, which is why knowledge of etiological agents of RTIs and their sensitivities to available drugs is of immense value to the selection and use of antimicrobial agents and to the development of appropriate prescribing policies. ${ }^{16}$ To our knowledge, there is limited information on the prevalence of various bacterial pathogens and their antibiotic resistance patterns in South India. This study was conducted to determine the etiological agents of RTIs in the tertiary health care facility, Narayana Medical College, Nellore, India and their antimicrobial susceptibility pattern to some commonly prescribed antibiotics at the hospital. It is hoped that the results will provide useful information which would be used in the formulation of policies for the rational and effective use of the antimicrobial agents in view of their reported effectiveness against a wide range of pathogens and propensity of bacteria to develop resistance to the drugs.

\section{METHODS}

\section{Study population}

The study population, were patients who attended the Hospital of Narayana Medical College of Nellore in Andhra Pradesh of India either as inpatient or out patient with symptoms suggestive of RTIs. All patients had clinical evidence of respiratory tract infections, as determined by the treating doctors. Only a single positive culture per patient was included in the analysis. Patients who have not been taking antibiotics of any kind at least for one week preceding the study were included. Institutional ethical committee clearance was obtained.

\section{Specimen collection}

The specimens were collected aseptically from 550 (Sputum 396 and Throat swab 154 samples) patients. All patients were instructed on how to collect the sputum samples aseptically and taken to the laboratory immediately for analysis. The sputum samples were collected into well-labeled sterile, wide mouthed glass bottles with screw cap tops as described by Kolawale et al. ${ }^{17}$ Using a sterile cotton wool swab moistened in peptone water, the surface of the infected throat was swabbed gently and then the swabs were transported to the laboratory. The study was carried out after taking informed consent of each patient from January 2011 to November 2011.

\section{Bacteriological analysis}

In the laboratory, each sample was inoculated on McConkey agar, Chocolate agar and Blood agar. The inoculum on the plate was streaked out for discrete colonies with a sterile wire loop, following standard procedures. ${ }^{18}$ The culture plates were incubated at 35 $37^{\circ} \mathrm{C}$ for $24 \mathrm{~h}$ and observed for growth through formation of colonies. All the bacteria were isolated and identified using morphological, microscopy and biochemical tests following standard procedures described by Sharma. ${ }^{19}$

\section{Standardization of microorganisms}

Culture was standardized according to the methods described by Baker and Thornsberg (1983) and the Clinical and Laboratory Standard Institute. ${ }^{20}$

\section{Antibiotic susceptibility testing}

The antibacterial susceptibility testing of the isolates was done using the Kirby-Bauer disk diffusion method ${ }^{21}$ following the definition of the Clinical and Laboratory 
Standards Institute. ${ }^{20}$ A sterile cotton swab was dipped into the standardized solution of bacterial cultures and used for evenly inoculating Mueller-Hinton plates (Himedia, Mumbai) and allowed to dry. Then, the commercial antibiotic discs were gently and firmly placed on the agar plates, which were then left at room temperature for $1 \mathrm{~h}$ to allow diffusion of the antibiotics into the agar medium. The plates were then incubated at $35-37^{\circ} \mathrm{C}$ for $24 \mathrm{~h}$.

Zones of growth inhibition (zone diameter) were then measured to the nearest millimeter and recorded. Isolates were classified as either resistant $(\leq 13 \mathrm{~mm})$ or intermediate $(14-18 \mathrm{~mm})$ sensitive or sensitive $(\geq 19 \mathrm{~mm})$ based on the standard intermediate chart updated according to the standard of the Clinical and Laboratory Standard Institute (2006). Sensitive and intermediately sensitive isolates were grouped together for analysis in this study.

Some laboratory strains of known sensitivity of Staphylococcus aureus, Enterococcus faecalis, Escherichia coli and Pseudomonas aeruginosa were used as quality control strains for the antimicrobial discs.

\section{RESULTS}

The bacteria isolated from the samples included klebsiella spp $(51.1 \%)$, pseudomonas $(19.1 \%)$, E. coli $(8.6 \%)$, Acenobacter spp (7.3\%), Staphylococcal aureus $(6.9 \%)$, streptococcal pneumonia $(5.8 \%)$ and enterococci $(1.3 \%)$ in order of ranking (Table 1$)$.

The susceptibility pattern of isolates to various routinely prescribed antibiotics is shown in Table 2. Klebsiella was the most prevalent bacteria with a susceptibility of 88.5 \%to Cefoperazone with Sulbactam, $88.3 \%$ Imipenem, 87 $\%$ Piperacillin + Tazobactum, $81.7 \%$ Meropenem, $72.5 \%$ Amikacin, $68 \%$ Levofloxacin, $64.5 \%$ Ciprofloxacin and $59.4 \%$ Gentamicin. Pseudomonas was highly susceptible to Piperacillin + Tazobactum $(91.2 \%)$, Meropenem (90.0\%), Cefoperazone + Sulbactam $(89.1 \%)$, Amikacin (82.6\%), Imipenem (82.5\%), Levofloxacin (76.9\%), Ciprofloxacin $(73.4 \%)$, Gentamicin $(58.3 \%)$. The least prevalent bacteria were Enterococci $(1.3 \%)$ and were susceptible to Amoxycillin + Clavulanic acid (80\%). They were totally resistant to Ciprofloxacin, Penicillin G and Tetracycline.

Table 1: Prevalence of bacterial isolates in respiratory tract infections.

\begin{tabular}{|lllllll|}
\hline Bacteria & No. of isolates & $\%$ & Males & $\%$ & Females & $\%$ \\
\hline Klebsiella spp. & 238 & 51.1 & 137 & 53.5 & 101 & 48.1 \\
\hline Pseudomonas & 89 & 19.1 & 47 & 18.4 & 42 & 20.0 \\
\hline E. coli & 40 & 8.6 & 16 & 6.3 & 24 & 11.4 \\
\hline Acenobacter spp. & 34 & 7.3 & 18 & 7.0 & 6.6 & 7.6 \\
\hline Staph. aureus & 32 & 6.9 & 17 & 11 & 15 & 7.2 \\
\hline Strep. pneumoniae & 27 & 5.8 & 16 & 6.3 & 11 & 5.2 \\
\hline Enterococci & 6 & 1.3 & 2.0 & 5 & 1 & 0.5 \\
\hline Total & 466 & 100 & 256 & 100 & 210 & 100 \\
\hline
\end{tabular}

\section{DISCUSSION}

Out of 550 samples analyzed, in 466 samples various bacteria were isolated giving a prevalence rate of $84.7 \%$. This consisted of $54.9 \%$ from male patients and $45.1 \%$ from females (Table 1). The results show that RTIs were more prevalent in males than in females. According to Doddann-navar (1985) as reported by Gauchan et al. ${ }^{7}$, the reason for the high risk in males of RTI is attributable to decreased local immunity in the respiratory tract due to smoking, use of tobacco, alcohol consumption etc.
Among the bacterial isolates, Klebsiella spp. (51.1\%) was the most common isolate followed by Pseudomonas (19.1\%), E. coli (8.6\%), Acenobacter spp (7.3\%), Staphylococcal aureus $(6.9 \%)$, streptococcal pneumonia $(5.8 \%)$ and enterococci $(1.3 \%)$ respectively. Similar to Akingbade OA et al $(2012)^{22}$, Staph. aureus and Strep. pneumonia are the only two Gram positive isolates obtained in this study whereas $\mathrm{K}$. pneumoniae was predominant of Gram negative isolate. The finding in this work was in contrast to the study of Gauchan et $\mathrm{al}^{7}$ and Jafari et $\mathrm{al}^{23}$ who reported klebsiella spp. as the second predominant Gram negative bacterial isolates. 
Table 2: Antimicrobial susceptibility among community acquired respiratory pathogens.

\begin{tabular}{|c|c|c|c|c|c|c|c|c|c|c|c|c|c|c|c|c|c|c|c|c|c|}
\hline \multicolumn{22}{|l|}{ Pathogens } \\
\hline \multirow[t]{2}{*}{ Antimicrobials } & \multicolumn{3}{|c|}{ Klebsiella } & \multicolumn{3}{|c|}{ Pseudomonas } & \multicolumn{3}{|c|}{ E. coli } & \multicolumn{3}{|c|}{ Acenobacter } & \multicolumn{3}{|c|}{ Stre. pneumonia } & \multicolumn{3}{|c|}{ Staph. aureus } & \multicolumn{3}{|c|}{ Enterococci } \\
\hline & $\mathrm{T}$ & $\mathrm{S}(\%)$ & $\mathrm{R}(\%)$ & $\mathrm{T}$ & $\mathrm{S}(\%)$ & $\mathrm{R}(\%)$ & $\mathrm{T}$ & $\mathrm{S}(\%)$ & $\mathrm{R}(\%)$ & $\mathrm{T}$ & $\mathrm{S}(\%)$ & $\mathrm{R}(\%)$ & $\mathrm{T}$ & $\mathrm{S}(\%)$ & $\mathrm{R}(\%)$ & $\mathrm{T}$ & $\mathrm{S}(\%)$ & $\mathrm{R}(\%)$ & $\mathrm{T}$ & $\mathrm{S}(\%)$ & $\mathrm{R}(\%)$ \\
\hline Penicillin G & 5 & 20.0 & 80.0 & - & - & - & - & - & - & - & - & - & 26 & 11.5 & 88.5 & 25 & 32.0 & 68.0 & 8 & - & 100 \\
\hline Ampicillin & 143 & 6.3 & 93.7 & 35 & - & 100 & 31 & 12.9 & 87.1 & 19 & 5.3 & 94.7 & 16 & 56.3 & 43.7 & 6 & 66.7 & 33.3 & 8 & 12.5 & 87.5 \\
\hline Cefotaxime & 214 & 27.6 & 72.4 & 63 & 35.0 & 65.0 & 34 & 14.7 & 85.3 & 27 & 11.1 & 88.9 & 4 & 75.0 & 25.0 & 10 & 40.0 & 60.0 & - & - & - \\
\hline Cefepime & 199 & 31.7 & 68.3 & 57 & 40.4 & 59.6 & 37 & 32.4 & 67.6 & 26 & 15.4 & 84.6 & 6 & 33.3 & 66.7 & 33 & 42.4 & 57.6 & - & - & - \\
\hline Cotrimoxazole & 129 & 32.5 & 67.5 & 39 & 7.7 & 92.3 & 24 & 29.2 & 70.8 & 21 & 14.3 & 85.7 & 27 & 33.3 & 66.7 & 23 & 56.5 & 43.5 & 6 & 16.7 & 83.3 \\
\hline Ciprofloxacin & 200 & 64.5 & 35.5 & 75 & 73.4 & 26.6 & 41 & 43.9 & 56.1 & 28 & 42.8 & 57.2 & 18 & 88.9 & 11.1 & 18 & 66.7 & 33.3 & 1 & - & 100 \\
\hline Levofloxacin & 50 & 68.0 & 32.0 & 13 & 76.9 & 23.1 & 6 & 50.0 & 50.0 & 9 & 22.2 & 77.8 & - & - & - & 5 & 60.0 & 40.0 & - & - & - \\
\hline Gentamicin & 59 & 59.4 & 40.6 & 24 & 58.3 & 41.7 & 14 & 57.1 & 42.9 & 9 & 44.4 & 55.6 & 2 & 50.0 & 50.0 & 11 & 63.6 & 36.4 & 2 & - & 100 \\
\hline Amikacin & 193 & 72.5 & 27.5 & 69 & 82.6 & 17.4 & 34 & 79.4 & 20.6 & 30 & 40.0 & 60.0 & 4 & 25.0 & 75.0 & 28 & 82.1 & 11.9 & - & - & - \\
\hline Tetracycline & 31 & 45.1 & 54.9 & 8 & 50.0 & 50.0 & 7 & 57.1 & 42.9 & 11 & 72.8 & 27.2 & 20 & 75.0 & 25.0 & 22 & 77.3 & 22.7 & 1 & - & 100 \\
\hline Amox + Clau & 164 & 20.2 & 79.8 & 23 & 13.0 & 87.0 & 34 & 26.5 & 73.5 & 22 & 9.0 & 91.0 & 24 & 87.5 & 12.5 & 24 & 83.3 & 16.7 & 8 & 75.0 & 25.0 \\
\hline Cef. + Sulb. & 166 & 88.5 & 11.5 & 46 & 89.1 & 10.9 & 31 & 93.6 & 6.4 & 20 & 60.0 & 40.0 & - & - & - & - & - & - & - & - & - \\
\hline Pipe. + Tazo. & 115 & 87.0 & 13.0 & 68 & 91.2 & 8.8 & 22 & 90.9 & 9.1 & 14 & 92.8 & 7.2 & - & - & - & - & - & - & - & - & - \\
\hline Imipenem & 162 & 88.3 & 11.7 & 57 & 82.5 & 17.5 & 34 & 94.1 & 5.9 & 22 & 54.5 & 45.5 & 3 & 100 & - & - & - & - & - & - & - \\
\hline Meropenem & 142 & 81.7 & 18.3 & 30 & 90.0 & 10.0 & 25 & 76.0 & 24.0 & 24 & 75.0 & 25.0 & 2 & 100 & - & - & - & - & - & - & \\
\hline
\end{tabular}

$\mathrm{T}-$ Number of isolates tested against each antimicrobial agent, $\mathrm{S}(\%)-$ Percent of isolates susceptible to antimicrobial agents, $\mathrm{R}(\%)-\mathrm{Percent}$ of isolates resistance to antimicrobial agents. Amox. + Clau. : Amoxycillin + Clavulanic acid, Cef. + Sulb. : Cefoperazone + Sulbactam, Pipe. + Tazo. : Piperacillin + Tazobactam

In a study carried out by $K$. Kousalya et $\mathrm{al}^{24}$ on the antimicrobial resistance of bacterial agents of the upper respiratory tract in South Indian population, $S$. aureus $(45.6 \%)$ was the most prevalent isolate followed by $\beta$ haemolytic Streptococci $(22.8 \%)$, K. pneumonia (14.9\%) and $\mathrm{P}$. aeruginosa $(8.33 \%)$.

All the isolates displayed variable sensitivity to different antibiotics tested as detailed in Table 2. The most effective antimicrobials for $\mathrm{K}$. pneumonia was Cefoperazone with Sulbactam $(88.5 \%)$, Imipenem $(88.3 \%)$, Piperacillin + Tazobactum $(87 \%)$, Meropenem (81.7\%), Amikacin (72.5\%), Levofloxacin (68\%), Ciprofloxacin $(64.5 \%)$ and Gentamicin (59.4\%). Least effective drug was Ampicillin (6.3\%).

Susceptibility pattern of Pseudomonas, E. coli, Strep. pneumoniae and Acenobacter is somewhat similar to $\mathrm{K}$. pneumoniae. Tetracycline was more effective $(92.8 \%)$ against Acenobacter.

Staph. aureus was more sensitive to Amikacin, Tetracycline, Amoxycillin + Clavulanic acid, Gentamicin, Cotrimoxazole and Cefepime. Only 6 Enterococci were isolated and sensitive to Amoxycillin + Clavulanic acid $(80 \%)$. They were totally resistant to Penicillin G, Ciprofloxacin, Gentamicin and Tetracycline.

The results of the sensitivity tests indicate that isolates showed highest sensitivity to Meropenem, Imipenem, Piperacillin + Tazobactum, Cefoperazone with Sulbactam, Amoxycillin + Clavulanic acid, Amikacin, Gentamicin, Levofloxacin, and Ciprofloxacin. High resistance was recorded for antimicrobials such as Penicillin G, Ampicillin, Cefotaxime, Cotrimoxazole and Cefepime.

The pattern of antibiotic sensitivity recorded in this study among Klebsiella spp., Pseudomonas aeruginosa, E. coli isolates is consistent with results obtained from other developing countries. ${ }^{7,22}$ Compared to most of the earlier studies the prevalence of Klebsiella is more in this study.

The incidence of bacterial resistance mediated by $\beta$ lactamase has been reported in several countries including Nigeria, South Africa. ${ }^{25-27}$ The clinical relevance of these enzymes is due to their ability of causing therapeutic failures. In our study combination of antibiotics with $\beta$ - lactamase inhibitors have been included, all of which are showing high sensitivity.

Resistance to Penicillin G and Ampicillin by respiratory tract pathogens in this study is of concern. High microbial resistance to ampicillin and penicillin have also been reported in Iran by Imani et al., ${ }^{8}$ Korea by Song et al., ${ }^{28}$ France, Germany and Japan by Schito et al. ${ }^{29}$

Data presented in this study indicate that some of the antibiotics commonly used to treat RTIs in the referral hospitals are still effective. The results show that antibiotic resistance in this locality is relatively low compared with other countries and regions throughout the world as determined by the global surveillance studies conducted by Morrissey et al. ${ }^{30}$ But, it is still important to periodically monitor the prevalence and antimicrobial 
sensitivity pattern before empirical therapy is initiated in hospitals.

In summary, most of the bacterial isolates remain susceptible to Cephalosporins and Fluoroquinolones, particularly more susceptible when given with $\beta$ - lactamase inhibitors.

The study provides important data, which can help to guide physicians in Nellore of Andhra Pradesh in India, to choose the appropriate treatment regimen for RTI. This study does not represent a surveillance study for other parts of India, since antibiotic sensitivity and resistance of bacterial pathogens may vary from place to place and time to time.

Accurate information on local epidemiology and antimicrobial resistance patterns of pathogens is essential to select a clinically effective antibiotic therapy for the infections.

\section{CONCLUSION}

The level of antibiotic resistance observed in this study is a serious public health problem and hence, brings to light the need for timely and proper diagnosis of the major microbial causes of the respiratory infections, in order to administer the appropriate therapy based on antibiotic susceptibility test of the causative agent.

The reason for the resistance may be due to indiscriminate and inappropriate use and abuse of drugs, adulteration of drugs and mutation of microorganisms and lack of appropriate infection control strategies.

Surveillance of bacterial infections and monitoring their antimicrobial susceptibility pattern must be carried out, from time to time, not only in tertiary hospitals, but also in small hospital settings.

There is also the need for further studies on antibiotic resistance using different antibiotic with a view to identifying one with which RTI pathogens are almost 100 $\%$ susceptible to. These types of data will help in designing and validating the accuracy of guidelines for empirical treatment of RTIs.

\section{ACKNOWLEDGEMENTS}

We sincerely thank the management and staff of the Dept. of Microbiology and Central Laboratory, Narayana Medical College, Nellore, AP, India.

Funding: None

Conflict of interest: None declared

Ethical approval: Institutional ethical committee

\section{REFERENCES}

1. Carroll KC. Laboratory diagnosis of lower respiratory tract infections: Controversy and conundrums. J Clin Microbiol 2002;40(9):3115-20.

2. Bipin Prajapati., Nitiben Talsania., Sonaliya, K. N. A study on prevalence of acute respiratory Tract infections (ARI) in under five children in Urban and rural communities of Ahmedabad District, Gujarat. Nat J Com Med 2011;2(2):255-259.

3. Jacobs, E., Dalhoff, A., and Korfmann, G. 2009. Susceptibility patterns of bacterial isolates from hospitalised patients with respiratory tract infections. Int. J. Antimicrob. Agents, 33: 52-57.

4. Sharma, R., Sharma, C. L., and Kapoor, B. 2005. Antibacterial resistance: Current problems and possible solutions. Indian Journal of Medical Sciences 59, 120-129.

5. World Health Organization. 2003. Disease Burden and Economics. Practical Approach to Lung Health (PAL). WHO.

6. Mizgerd JP. 2008. Acute lower respiratory tract infection. N. Engl. J. Med., 358: 716-727.

7. Gauchan P, Lekhak B, Sherchand JB. 2006. The Prevalence of lower respiratory tract infection in adults visiting Tribhuvan University Teaching Hospital. Journal of Institute of Medicine, 28(2):1014.

8. Imani R, Rouchi H, Ganji F. 2007. Prevalence of antibiotic resistance among bacteria isolates of lower respiratory tract infection in COPD Shahrekord - Iran, 2005. Pak. J. Med. Sc., 23: 438440 .

9. Tenever FC, McGowan JE Jr (1996). Reasons for the emergence of antibiotic resistance, Am. J. Med. Sci., 311: 9-16.

10. Hryniewicz K, Szezypa K, Sulikowska A, Jankowski K, Bethejeewska K, Hryniewicz (2001). Antibiotic susceptibility of bacterial strains isolated from urinary tract infections in Poland, J. Antimicrob. Chemother., 47: 773-780.

11. Kurutepe S, Surucuoghu S, Sezgin C, Gazi H, Gulay M, Ozbakkaloglu B (2005). Increasing antimicrobial resistance in E. coli isolates from community-acquired urinary tract infections during 1998-2003 in Manisa, Turkey. Jpn. J. Infect. Dis., 58: 159-161.

12. Kumari HBV, Nagarathna S, Chandramuki A. 2007. Antimicrobial resistance pattern among aerobic gram-negative bacilli of lower respiratory tract illness in the community. Thorax. 56:109-114.

13. Zafar A, Hussain Z, Lomama E, Sibiie S, Irfan S, Khan E (2008). Antibiotic susceptibility of pathogens isolated from patients with communityacquired respiratory tract infections in Pakistan-the active study. J. Ayub Med. Coll. Abbottabad.,20(1): 7-9.

14. Riley, C., and Riley, S. 2003. Influenza and pneumococcal disease in the community. Nursing Standard 18(4):45-51. 
15. Rudan, I., Boschi-Pinto, C., Biloglav, Z., Mulholland, K. and Campbell, H. 2008. Epidemiology and etiology of childhood pneumonia. Bulletin of the World Health. Org 86: 408-416.

16. El-Astal Z (2004). Bacterial pathogens and their antimicrobial susceptibility in Gaza Strip, Palestine. Pakistan. J. Med., 20(4):365-370.

17. Kolawale AS, Kolawale OM, Kandaki-Olukemi YT, Babatunde SK,Durowade KA, Kolawale CF (2009). Prevalence of urinary tract infections among patients attending Dalhatu Araf Specialist Hospital, Lafia, Nasarawa State, Nigeria. Int. J. Med. Sci., 1(5): 163-167.

18. Cheesborough M (2006). District Laboratory Practice in Tropical Countries Vol. II, Microbiology second edition Cambridge University Press., pp. 158-195.

19. Sharma, K., 2008. Manual of Microbiology: Tools and Techniques, [2nd Ed.] Ann Books Gopaljee Enterprises, Dehi, India. pp. 163-165; 181-7.

20. Clinical Laboratory Standard Institute (2006). Zone diameter Interpretive Standards and corresponding minimal inhibitory concentration (MIC) interpretive break point. Supplement M44-S1. Clinical and Laboratory Standard Institute, Wayne, PA.

21. Bauer AW, Kirby WM, Sharris JC, Jurck M (1966). Antibiotic susceptibility testing by a standard single disk method, Am. J. Clin. Pathol., 45: 493-496.

22. Akingbade OA, Ogiogwa JI, Okerentugba PO, Innocent-Adiele $\mathrm{HC}$, Onoh CC, Nwanze JC, Okonko IO. Prevalence and Antibiotic Susceptibility Pattern of Bacterial Agents Involved In Lower Respiratory Tract Infections in Abeokuta, Ogun State, Nigeria. Report and Opinion 2012; 4(5):25-30]. http://www.sciencepub.net/report.

23. Jafari J, Ranjbar R, Haghi-Ashtiani MT, Abedini M, Izadi M.2009. Prevalence and Antimicrobial susceptibility of Tracheal Bacterial strains isolated from Paediatric patients. Pakistan Journal of Biological Sciences, 12(5):455-458.

24. K. Kousalya, S. Thirumurugu, D. C. Arumainayagam, R. Manavalan, J. Vasantha, and C. Uma Maheswara Reddy. Antimicrobial resistance of bacterial agents of the upper respiratory tract in South Indian population. J Adv Pharm Technol Res. 2010 Apr;1(2):207-15.

25. Zeba B (2005). Overview of $\beta$-lactamase incidence on bacterial drug resistance, Afr. J. Biotechnol., 4(13): 1559-1562.

26. Onanuga A, Oyi AR, Olayinka BO, Onaolapo JA (2005). Prevalence of community- associated multiresistant Staphylococcus aureus among healthy women in Abuja, Nigeria. Afr. J. Biotechnol., 4: 942-945.

27. Nwanze P, Nwaru LM, Oranusi S, Dimkpa U, Okwu MU,Babatunde BB, Anke TA, Jatto W, Asagwara CE (2007). Urinary tract infection in Okada village: Prevalence and antimicrobial susceptibility pattern. Sci. Res. Essays., 2(4): 112116.

28. Song JH, Lee NY, Ichiyama S, Yoshida R, Hirakata Y, Fu W (1999). Spread of drug resistant Streptococcus pneumonia in Asian Countries: Asian Network for Surveillance of Resistant Pathogens (ANSORP) study. Clin. Infect. Dis., 28:1206-1211.

29. Schito GC, Debbia EA, Marchese A. The evolving threat of antibiotic resistance in Europe: new data from the Alexaner Profect. J Antimicrob Chemother 2000;46:TL.3-9.

30. Morrissey I, Robbins M, Viljoen L, Brown DFJ. Antimicrobial susceptibility of community acquired respiratory tract pathogens in the UK during 2002-2003 determined locally and centrally by BSAC methods. J Antimicrobial Chemother 2005;55:200-8.

doi:10.5455/2319-2003.ijbcp20131015

Cite this article as: CM Siddalingappa, L Kalpana, Puli S, TK Vasudha, Acharya A. Sensitivity pattern of bacteria causing respiratory tract infections in a tertiary care centre. Int J Basic Clin Pharmacol 2013;2:590-5. 